\title{
LEGISLACIÓN BÁSICA DE PROTECCIÓN DEL MEDIO AMBIENTE (SEGUNDO SEMESTRE 2020)
}

\author{
LAURA PRESICCE \\ Investigadora predoctoral \\ Departamento de Derecho Público - Universitat Rovira i Virgili \\ laura.presicce@urv.cat
}


SUMARIO: 1. Introducción. 2. Segundo Plan Nacional de Adaptación al Cambio Climático (PNACC) 2021-2030. 3. Medidas para la reactivación económica. 4. Real Decreto-ley 23/2020, de 23 de junio, por el que se aprueban medidas en materia de energía y en otros ámbitos para la reactivación económica. 4.1. Medidas para el desarrollo ordenado e impulso de las energías renovables. 4.2. Modificación de la Ley 24/2013, de 26 de diciembre, del Sector Eléctrico para introducir las nuevas figuras de almacenamiento, hibridación, agregadores independientes y comunidades de energía renovables. 4.3. Fomento de la eficiencia energética. 4.4. Modificaciones de la Ley 21/2013, de 9 de diciembre, de evaluación ambiental para agilizar el procedimiento de evaluación ambiental. 4.5. Medidas de impulso a la transición "justa". 5. Novedades normativas en ámbitos sectoriales. 5.1. En materia de residuos y suelos contaminados. 5.2. En materia de eficiencia energética. 5.3. En materia de sanidad vegetal y especies alóctonas. 6 . Ulteriores disposiciones de interés medioambiental.

\section{INTRODUCCIÓN}

El Gobierno español, a raíz de la declaración de la Organización Mundial de la Salud (OMS) de pandemia ocasionada por el virus COVID-19, declaró, el pasado 14 de marzo ${ }^{1}$, el Estado de Alarma, amparándose en el artículo cuarto, apartado b), de la Ley Orgánica 4/1981, de 1 de junio, de los estados de alarma, excepción y sitio². El estado de alarma fue levantado, después de más de tres meses, el pasado 21 de junio ${ }^{3}$. En plena pandemia, la prioridad del Gobierno en estos meses ha sido, sin duda, adoptar medidas de contención del virus, de transición a la mal llamada "nueva normalidad" y de reactivación económica. Con este telón de fondo, en el período que cubre esta crónica (1 de abril 2020 - 30 de septiembre 2020) se han aprobado importantes avances normativos en tema de energía renovable, de gestión de residuos y de eficiencia energética. Además, ha sido aprobado el segundo Plan Nacional de Adaptación al Cambio Climático para el periodo 2021-2030 y la Estrategia Española de Economía Circular, denominada "España Circular 2030".

Sin embargo, antes de proceder con nuestro análisis de la normativa de interés aprobada en los últimos seis meses, creemos importante resaltar que, en el

\footnotetext{
${ }^{1}$ Real Decreto 463/2020, de 14 de marzo, por el que se declara el estado de alarma para la gestión de la situación de crisis sanitaria ocasionada por el COVID-19. [BOE núm. 67, de 14 de marzo de 2020].

${ }^{2}$ Esta disposición habilita al Gobierno para, en el ejercicio de las facultades que le atribuye el artículo 116.2 de la Constitución, declarar, en todo o parte del territorio nacional el estado de alarma, en caso de crisis sanitarias que supongan alteraciones graves de la normalidad.

${ }^{3}$ Real Decreto 555/2020, de 5 de junio, por el que se prorroga el estado de alarma declarado por el Real Decreto 463/2020, de 14 de marzo, por el que se declara el estado de alarma para la gestión de la situación de crisis sanitaria ocasionada por el COVID-19. [BOE núm. 159, de 6 de junio de 2020].
} 
periodo que cubre la crónica, la Dirección General de Políticas Energéticas y Minas ha autorizado el cierre de cinco centrales térmicas (en concreto, de la Central Térmica de Teruel (Andorra), de los grupos 3, 4 y 5 de la Central Térmica de Compostilla II (León), de la Central Térmica de Lada 4 (Asturias), de la Central Térmica de Meirama (A Coruña) y de la Central Térmica de Puente Nuevo (Córdoba $)^{4}$. Por otro lado, también cabe mencionar que se ha otorgado la renovación de la autorización de explotación de la Central Nuclear de Almaraz ${ }^{5}$, en Cáceres, hasta noviembre 2027 (Unidad I) y octubre 2028 (Unidad II), fechas en las que se producirá el cese definitivo de explotación de estas Unidades. Asimismo, se ha renovado la autorización de la Central Nuclear de Vandellós II6, hasta julio de 2030 , con la posibilidad de solicitar, en este caso, una nueva autorización en 2029.

Por otra parte, también merecen mención dos proyectos de ley en materia de cambio climático que se están tramitando en el Congreso de los Diputados: el Proyecto de Ley de cambio climático y transición energética ${ }^{7}$ y el Proyecto de Ley por la que se modifica la Ley $1 / 2005$, de 9 de marzo, por la que se regula el régimen del comercio de derechos de emisión de gases de efecto invernadero,

\footnotetext{
${ }^{4}$ Acerca del cierre de las centrales térmicas, señalamos las resoluciones de la Dirección General de Política Energética y Minas,

a) de 29 de junio de 2020, por la que se autoriza a Endesa Generación, SA, el cierre de la Central Térmica de Teruel, en el término municipal de Andorra (Teruel).

b) de 29 de junio de 2020, por la que se autoriza a Endesa Generación, SA, el cierre de los grupos 3, 4 y 5 de la Central Térmica de Compostilla II, en el término municipal de Cubillos del Sil (León).

c) de 31 de julio de 2020, por la que se autoriza a Iberdrola Generación Térmica, SLU, el cierre de la Central Térmica de Lada 4, de 350 MW de potencia nominal, en La Felguera, Langreo (Asturias).

d) de 31 de julio de 2020, por la que se autoriza a Naturgy Generación, SLU, el cierre de la Central Térmica de Meirama, en Cerceda (A Coruña).

e) de 31 de julio de 2020, por la que se autoriza a Viesgo Producción, SL, el cierre de la Central Térmica de Puente Nuevo, en Espiel (Córdoba).

${ }^{5}$ Orden TED/773/2020, de 23 de julio, por la que concede la renovación de la autorización de explotación de la Central Nuclear de Almaraz, Unidades I y II. [BOE núm. 212, de 6 de agosto 2020].

${ }^{6}$ Orden TED/774/2020, de 23 de julio, por la que concede la renovación de la autorización de explotación de la Central Nuclear de Vandellós II. [BOE núm. 212, de 6 de agosto de 2020].

${ }^{7}$ Consultable en:

$<$ http://www.congreso.es/portal/page/portal/Congreso/Congreso/Iniciativas? piref73 2148295 731335437 1335437.next page=/wc/servidorCGI\&CMD=VERLST\&BASE=IW14\&FMT=INITX DSS.fmt\&DOCS $=1$ -

1\&DOCORDER=FIFO\&OPDEF=ADJ\&QUERY=\%28121\%2F000019*.NDOC.\%29> (Última consulta: 06.10 .2020$)$.
} 
para intensificar las reducciones de emisiones de forma eficaz en relación con los costes ${ }^{8}$.

\section{SEGUNDO PLAN NACIONAL DE ADAPTACIÓN AL CAMBIO CLIMÁTICO (PNACC) 2021-2030}

Para hacer frente a los compromisos internacionales asumidos por España en materia de lucha contra el cambio climático, el 22 de septiembre, el Consejo de Ministros aprobó segundo Plan Nacional de Adaptación al Cambio Climático (en adelante PNACC) 2021-2030 , uno de los instrumentos fundamentales que forman parte del marco estratégico estatal en materia de energía y clima. La aprobación del segundo PNACC fue, además, uno de los objetivos prioritarios apuntados por el Gobierno en su Declaración ante la Emergencia Climática y Ambiental del 21 de enero de $2020^{10}$.

EI PNACC, como "instrumento de planificación básico para promover la acción coordinada y coherente frente a los efectos del cambio climático en España", comprende un amplio abanico de estrategias y medidas en diferentes sectores para la adaptación al cambio climático en España, en una doble óptica: evitar, o más bien reducir, los impactos potenciales derivados del cambio climático, por un lado, y mejorar la respuesta tras los eventuales daños causado por el mismo, por el otro. Al mismo tiempo, siendo la adaptación una línea de acción climática con enorme potencial para contribuir también a la recuperación de los daños causados por la pandemia de la COVID-19, el PNACC se perfila también como marco auxiliar para la recuperación de los daños causados por la pandemia.

En cuanto a su contenido, tras la definición de una serie de principios orientadores que deberán guiar las políticas y medidas en materia de adaptación (cap. 5), el capítulo 6 identifica los instrumentos claves para lograr una acción

\footnotetext{
${ }^{8}$ Consultable en: <http://www.congreso.es/portal/page/portal/Congreso/Congreso/Iniciativas? piref73 2148295 731335437 1335437. next page=/wc/servidorCGI\&CMD=VERLST\&BASE=IW14\&PIECE=IWA 4\&FMT=INITXD1S.fmt\&FORM1=INITXLBA.fmt\&QUERY=121.cini. +no+\%40fcie+no+concluido.f ase.\&DOCS $=10-10>$ (Última consulta: 06.10.2020).

${ }^{9}$ Consultable en <https://www.miteco.gob.es/images/es/pnacc-2021-2030 tcm30-512156.pdf> (Última consulta: 28.09.2020).

${ }_{10}$ Vid. Laura Presicce, "Legislación básica de protección del medio ambiente. Primer semestre 2020", Revista Catalana de Dret Ambiental, Vol. XI Núm. 1, 2020, pp. 3 ss.
} 
eficaz en materia de adaptación: generación de conocimiento, integración de la adaptación en planes, programas y normativa sectorial, movilización de actores y seguimiento y evaluación.

En el capítulo 7 se concretan los 18 ámbitos sectoriales de trabajo y, para cada uno de ellos, se definen los objetivos y las líneas de acción a desarrollar para alcanzar los objetivos (Anexo 1). Además de la acción de carácter sectorial, el PNACC define también 7 aspectos transversales (capítulo 8), que deberán ser impulsados en todos los ámbitos sectoriales ${ }^{11}$.

Debido a la brevedad que impone un trabajo de esta índole, se ha considerado oportuno redactar una tabla con las líneas de acciones más importantes de los ámbitos sectoriales que pueden afectar al medio ambiente.

\begin{tabular}{|c|c|}
\hline Ámbito sectorial & Línea de acción \\
\hline \multirow{2}{*}{$\begin{array}{l}\text { 1. Clima y } \\
\text { escenarios } \\
\text { climáticos }\end{array}$} & 1.3. Proyecciones de cambio climático regionalizadas para España \\
\hline & 1.5. Capacitación para el uso de información climática \\
\hline \multirow[t]{2}{*}{ 2. Salud humana } & $\begin{array}{l}\text { 2.1. Integración del cambio climático en el Plan Nacional de Salud } \\
\text { y Medio ambiente } \\
\text { - El Plan Nacional de Salud y Medio ambiente, que } \\
\text { desarrollará la Ley } 33 / 2011 \text {, de } 4 \text { de octubre, General de Salud } \\
\text { Pública, describirá los principales factores ambientales que } \\
\text { influyen en la salud humana y establecerá los objetivos y las } \\
\text { líneas de intervención del Sistema Nacional de Salud en esta } \\
\text { materia. }\end{array}$ \\
\hline & $\begin{array}{l}\text { 2.3. Preparación y respuesta frente a enfermedades infecciosas y } \\
\text { parasitarias favorecidas por el cambio del clima }\end{array}$ \\
\hline
\end{tabular}

${ }^{11}$ Se trata de vulnerabilidad territorial, vulnerabilidad social, efectos transfronterizos, integración del enfoque de género, prevención de la maladaptación y eliminación de incentivos perversos, costes y beneficios de la adaptación y de la inacción, orientación a la acción. Véase, para más detalles, Plan Nacional de Adaptación al Cambio Climático 2021-2030, pp. 68 y ss. 


\begin{tabular}{|c|c|}
\hline & $\begin{array}{l}\text { 2.4. Actuaciones preventivas ante episodios de contaminación } \\
\text { atmosférica }\end{array}$ \\
\hline \multirow[t]{6}{*}{$\begin{array}{l}\text { 3. Agua y } \\
\text { recursos hídricos }\end{array}$} & $\begin{array}{l}\text { 3.1. Ampliación y actualización del conocimiento sobre los } \\
\text { impactos potenciales del cambio climático en la gestión del agua y } \\
\text { los recursos hídricos. } \\
\text { - Los planes hidrológicos deberán incorporar, además de } \\
\text { la valoración del posible efecto del cambio climático sobre los } \\
\text { recursos hídricos naturales de cada demarcación, otros aspectos } \\
\text { relevantes de la gestión del agua, como los usos del agua, la } \\
\text { calidad del agua y de los ecosistemas, o la probabilidad de } \\
\text { ocurrencia de eventos extremos. }\end{array}$ \\
\hline & $\begin{array}{l}\text { 3.2. Integración de la adaptación al cambio climático en la } \\
\text { planificación hidrológica y la gestión del ciclo integral del agua }\end{array}$ \\
\hline & $\begin{array}{l}\text { 3.3. Gestión contingente de los riesgos por sequías integrada en la } \\
\text { planificación hidrológica y gestión del agua } \\
\text { - Reforzar el papel de los planes hidrológicos de cuenca } \\
\text { en la gestión de la escasez estructural, entendida como un } \\
\text { problema crónico para atender las demandas con los recursos } \\
\text { disponibles, debiendo diferenciarse plenamente de la gestión de } \\
\text { la escasez coyuntural. } \\
\text { - Desarrollar legislativamente el concepto de sequía y su } \\
\text { regulación, no mencionados en el Texto Refundido de la Ley de } \\
\text { Aguas. }\end{array}$ \\
\hline & $\begin{array}{l}\text { 3.4. Gestión coordinada y contingente de los riesgos por } \\
\text { inundaciones }\end{array}$ \\
\hline & $\begin{array}{l}\text { 4.1. Incorporación del factor cambio climático en las Estrategias } \\
\text { nacionales de conservación y en los planes de conservación y } \\
\text { recuperación de especies amenazadas }\end{array}$ \\
\hline & $\begin{array}{l}\text { 4.2. Planificación y gestión de áreas protegidas con criterios } \\
\text { adaptativos }\end{array}$ \\
\hline
\end{tabular}




\begin{tabular}{|c|c|}
\hline \multirow{2}{*}{$\begin{array}{l}4 . \quad \text { Patrimonio } \\
\text { Natural, } \\
\text { biodiversidad y } \\
\text { áreas protegidas }\end{array}$} & $\begin{array}{l}\text { - Incorporación de la adaptación al cambio climático en } \\
\text { los principales instrumentos de planificación y gestión de las } \\
\text { áreas protegidas. }\end{array}$ \\
\hline & $\begin{array}{l}\text { 4.5. Incorporación del factor cambio climático en la conservación } \\
\text { de los tipos de hábitats naturales y seminaturales y en su gestión } \\
\text { adaptativa } \\
\text { - Las actuaciones sobre hábitats de interés comunitario } \\
\text { deben estar explicitadas en los planes o instrumentos de gestión } \\
\text { de los espacios Natura } 2000 \text { correspondientes. } \\
\text { - Las Estrategias y los planes de conservación y } \\
\text { restauración de los tipos de hábitats incluidos en el Catálogo } \\
\text { Español de Hábitats en Peligro de Desaparición deberán } \\
\text { incorporar medidas adecuadas para su conservación frente a los } \\
\text { efectos que se prevé pueda causar el cambio climático. }\end{array}$ \\
\hline \multirow{5}{*}{$\begin{array}{l}5 . \quad \text { Forestal, } \\
\text { desertificación, caza } \\
\text { y pesca continental }\end{array}$} & $\begin{array}{l}\text { 5.1. Integración del cambio climático en los instrumentos de } \\
\text { planificación con implicaciones en el mantenimiento y mejora de } \\
\text { los recursos forestales }\end{array}$ \\
\hline & $\begin{array}{l}\text { 5.2. Revisión y actualización de las directrices y normas de gestión } \\
\text { forestal } \\
\text { - Por ejemplo, en las directrices básicas comunes de } \\
\text { gestión forestal sostenible (AGE), en instrucciones de ordenación } \\
\text { de montes (CCAA) o en modelos tipo de gestión forestal (CCAA). }\end{array}$ \\
\hline & $\begin{array}{l}\text { 5.3. Fomento de la integración del cambio climático en las políticas } \\
\text { y medidas relativas a la actividad cinegética y a la pesca } \\
\text { continental }\end{array}$ \\
\hline & $\begin{array}{l}\text { 5.4. Fomento de la prevención de la desertificación y la } \\
\text { restauración de tierras degradadas }\end{array}$ \\
\hline & $\begin{array}{l}\text { 5.5. Integración de las proyecciones climáticas y medidas de } \\
\text { adaptación en las políticas y medidas de lucha contra incendios } \\
\text { forestales }\end{array}$ \\
\hline
\end{tabular}




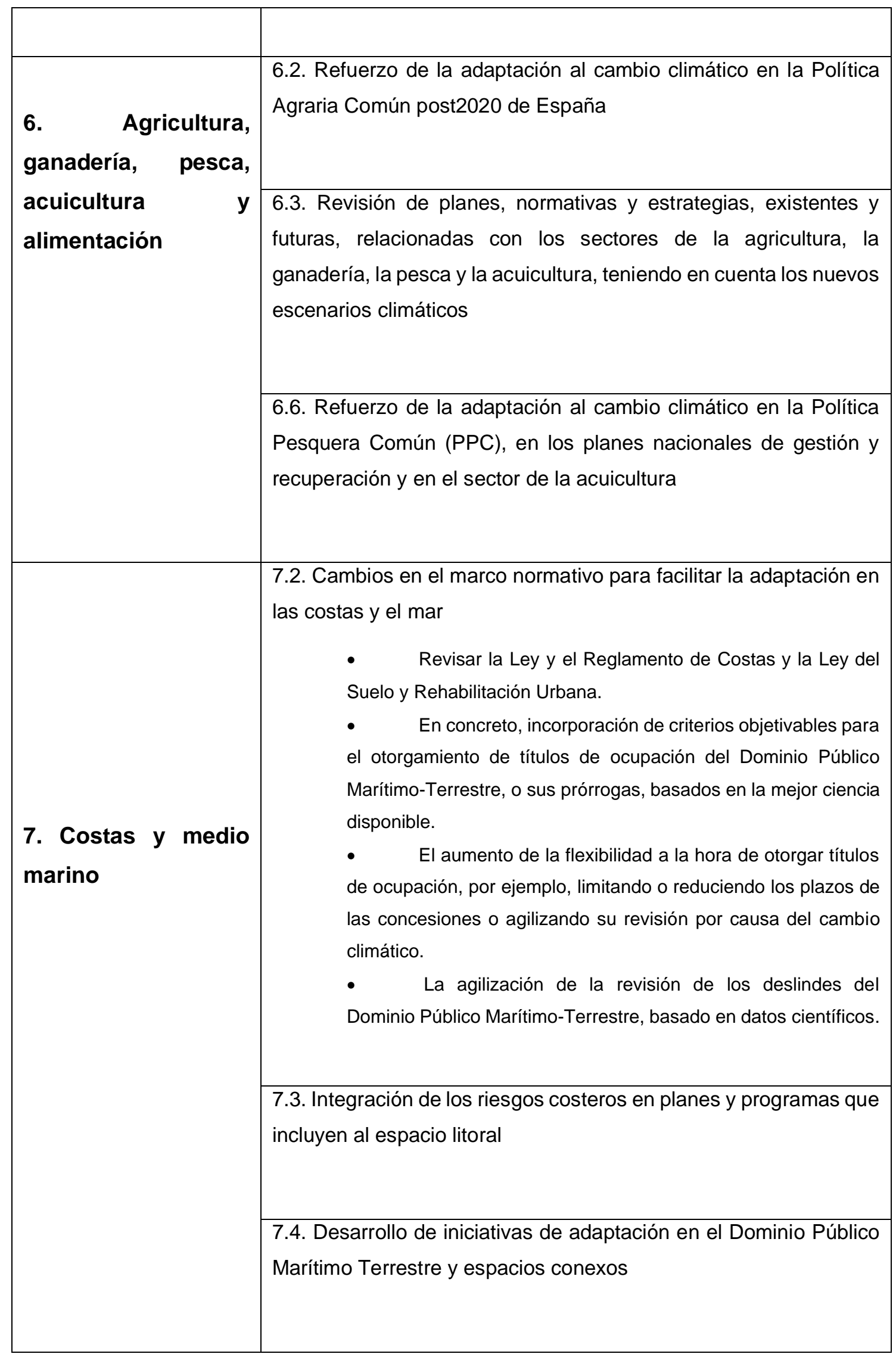




\begin{tabular}{|c|c|}
\hline \multirow{3}{*}{$\begin{array}{l}8 . \\
\text { urbanismo } \\
\text { edificación }\end{array}$} & $\begin{array}{l}\text { 8.1. Vinculación y refuerzo entre la Agenda Urbana Española y el } \\
\text { Plan Nacional de Adaptación al Cambio Climático, como marcos } \\
\text { de gobernanza }\end{array}$ \\
\hline & $\begin{array}{l}\text { 8.2 Integración de la adaptación al cambio climático en la } \\
\text { planificación territorial y urbana } \\
\text { - Además de integrar los riesgos derivados del cambio } \\
\text { climático en la planificación territorial y urbanística, es necesario } \\
\text { incorporar a la planificación el concepto de infraestructuras } \\
\text { verdes urbanas y azules, como soluciones multifuncionales } \\
\text { basadas en la naturaleza, que resuelven problemas urbanos } \\
\text { como la mejora de la biodiversidad, la gestión de zonas } \\
\text { inundables, la reducción de islas de calor, la lucha contra el } \\
\text { cambio climático o la mejora de la calidad del aire. } \\
\text { - La Ley de Cambio Climático y Transición Energética } \\
\text { intervendrá en este sentido. Además, es necesario adaptar la } \\
\text { normativa urbanística de las CCAA. }\end{array}$ \\
\hline & $\begin{array}{l}\text { 8.3. Integración de la adaptación al cambio climático en el sector } \\
\text { de la edificación } \\
\text { - Actualización del Código Técnico de la Edificación } \\
\text { (actualmente sometido al trámite de información pública). }\end{array}$ \\
\hline \multirow[t]{3}{*}{ 10. Energía } & $\begin{array}{l}\text { 10.1. Integración en la planificación y gestión energética de los } \\
\text { cambios en el suministro de energía primaria derivados del cambio } \\
\text { climático }\end{array}$ \\
\hline & $\begin{array}{l}\text { 10.2./10.3. Prevención de los impactos del cambio climático en la } \\
\text { generación de electricidad y en el transporte, almacenamiento y } \\
\text { distribución de la energía }\end{array}$ \\
\hline & $\begin{array}{l}\text { 10.4. Gestión de los cambios en la demanda eléctrica asociados al } \\
\text { cambio climático }\end{array}$ \\
\hline $\begin{array}{l}\text { 11. Movilidad y } \\
\text { transporte }\end{array}$ & $\begin{array}{l}\text { 11.2. Integración de los efectos del cambio climático en la } \\
\text { normativa para el cálculo y diseño de infraestructuras del } \\
\text { transporte }\end{array}$ \\
\hline
\end{tabular}




\begin{tabular}{|c|c|}
\hline $\begin{array}{l}\text { 12. Industria y } \\
\text { servicios }\end{array}$ & $\begin{array}{l}\text { 12.1. Integración de la adaptación en la legislación sectorial y los } \\
\text { planes de industrialización } \\
\text { - Inclusión de la adaptación al Cambio Climático en la Ley } \\
\text { de Industria y en la Estrategia Industrial. }\end{array}$ \\
\hline \multirow[t]{2}{*}{ 13. Turismo } & $\begin{array}{l}\text { 13.1. Integración de la adaptación en los planes, programas y } \\
\text { estrategias del ámbito del turismo }\end{array}$ \\
\hline & $\begin{array}{l}\text { 13.3. Definición de modelos turísticos más sostenibles y resilientes } \\
\text { a los impactos del cambio climático }\end{array}$ \\
\hline $\begin{array}{l}14 . \quad \text { Sistema } \\
\text { financiero, actividad } \\
\text { aseguradora }\end{array}$ & $\begin{array}{l}\text { 14.1. Incorporación de la adaptación al cambio climático en las } \\
\text { iniciativas de finanzas sostenibles } \\
\text { - A tal propósito, el Proyecto de Ley de Cambio Climático } \\
\text { y Transición Energética prevé (art. 28) la integración del riesgo } \\
\text { del cambio climático para empresas entidades de crédito, } \\
\text { entidades aseguradoras y reaseguradoras y sociedades por } \\
\text { razón de tamaño y determina el contenido de dichos informes. } \\
\text { Asimismo, el artículo } 29 \text { prevé que el Banco de España, junto con } \\
\text { la Comisión Nacional del Mercado de Valores, y la Dirección } \\
\text { General de Seguros y Fondos de Pensiones, elabore un informe } \\
\text { sobre la evaluación del riesgo para el sistema financiero español } \\
\text { derivado del cambio climático. }\end{array}$ \\
\hline $\begin{array}{l}\text { 15. Reducción del } \\
\text { riesgo de desastres }\end{array}$ & $\begin{array}{l}\text { 15.2. Integración de criterios adaptativos en las políticas y medidas } \\
\text { de reducción de riesgo de desastres y en las actuaciones post- } \\
\text { desastre }\end{array}$ \\
\hline \multirow{2}{*}{$\begin{array}{l}\text { 18. Paz, seguridad y } \\
\text { cohesión social }\end{array}$} & $\begin{array}{l}\text { 18.1. Promoción de la paz y la seguridad frente a los impactos del } \\
\text { cambio climático a nivel nacional }\end{array}$ \\
\hline & $\begin{array}{l}\text { 18.2. Integración de la adaptación al cambio climático en la } \\
\text { prevención, gestión y resolución de conflictos y crisis } \\
\text { internacionales y la construcción de una sociedad global pacífica, } \\
\text { justa e inclusiva }\end{array}$ \\
\hline
\end{tabular}




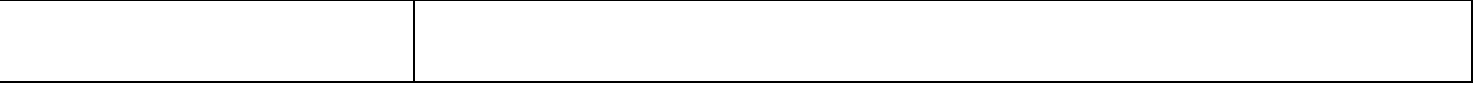

Fuente: elaboración propia.

Finalmente, el capítulo 9 abarca los principales instrumentos y acciones orientadas a reforzar la financiación de la adaptación ${ }^{12}$. A todo ello cabe añadir los instrumentos de información y seguimiento de las políticas públicas de adaptación y del propio plan (capítulo 10), como son los Informes sobre riesgos climáticos, los Informes sectoriales de adaptación y los Informes de Seguimiento del PNACC. Estos últimos, en concreto, se configuran como recopilaciones informativas sobre las acciones desarrolladas en el marco del PNACC en un periodo de tiempo definido y contienen, además, retos y perspectivas de futuro.

En relación con el sistema de gobernanza, para permitir e impulsar la acción coordinada y coherente de los actores involucrados, se prevén, por un lado, programas de trabajo, seminarios monográficos y planes sectoriales territoriales que deben redactar los diferentes actores (capítulo 11); así como foros específicos de carácter estable, bajo la guía de la Oficina Española de Cambio Climático (OECC), para mejorar la coordinación, el asesoramiento y la participación en materia de adaptación. Concretamente, se menciona al Grupo de Trabajo de Impactos y Adaptación (GTIA), un foro técnico, ya existente, de coordinación entre departamentos de la Administración General del Estado y las Comunidades Autónomas y el nuevo Comité de Impactos, Riesgos y Adaptación (CIRA). Este último será considerado como un grupo de trabajo del Comité de Expertos de Cambio Climático y Transición Energética, previsto en el proyecto de Ley de Cambio Climático y Transición Energética y se compondrá de personas procedentes del sector académico, de las organizaciones no gubernamentales, de la gestión pública y de las empresas (en especial pymes).

\footnotetext{
12 Entre ellas, destacamos las medidas específicas de recuperación en el marco de Next Generation EU y el Marco Financiero Plurianual 2021- 27 de la Unión Europea (con sus fondos europeos FEDER, FEAGA, FEADER y FEMP, y sus programas europeos LIFE y Horizonte Europa), así como los fondos nacionales (por ejemplo, PIMA ADAPTA, el Plan de Impulso al Medio Ambiente para la Adaptación al Cambio Climático).
} 
Resulta interesante destacar que el segundo PNACC ha sido precedido por una evaluación ${ }^{13}$ del precedente PNACC, llevada a cabo por un grupo asesor, tras la cual se han detectado una serie de "temas emergentes", entre los cuales la influencia de factores sociales y demográficos en la vulnerabilidad ante el cambio climático y la consideración de los impactos transnacionales del cambio climático.

\section{MEDIDAS PARA LA REACTIVACIÓN ECONÓMICA}

Para hacer frente a la fuerte contracción económica provocada a raíz de las restricciones a la actividad y la movilidad, necesarias para controlar la transmisión del virus, el Gobierno y la mayoría de CCAA, en ejercicio de sus competencias, han puesto en marcha una serie de políticas de apoyo al tejido productivo y social. Entre las medidas estatales destacamos:

- $\quad$ El Real Decreto-ley 11/2020, de 31 de marzo, por el que se adoptan medidas urgentes complementarias en el ámbito social y económico para hacer frente al COVID-1914, que establece, entre otras cosas, un amplio número de medidas para garantizar la continuidad del suministro energético y de agua para los hogares, para toda la duración del estado de alarma. La garantía de suministro básico fue posteriormente ampliada hasta el 30 de septiembre, por la Disposición Final Novena del Real Decreto-ley 25/2020, de 3 de julio.

- $\quad$ El Real Decreto-ley 24/2020, de 26 de junio, de medidas sociales de reactivación del empleo y protección del trabajo autónomo y de competitividad del sector industrial ${ }^{15}$, que refuerza las medidas de apoyo al sector industrial intensivo en el uso de la energía eléctrica, creando el Fondo Español de Reserva para Garantías Electrointensivas (FERGEI).

- El Real Decreto-ley 25/2020, de 3 de julio, de medidas urgentes para apoyar la reactivación económica y el empleo ${ }^{16}$, que ha presentado, entre

\footnotetext{
${ }^{13}$ El Informe de Evaluación del Plan Nacional de Adaptación al Cambio Climático puede ser consultado en <https://www.miteco.gob.es/es/cambio-climatico/temas/impactos-vulnerabilidady-adaptacion/informeevaluacion pnacc tcm30-499212.pdf> (última consulta: 29.09.2020).

${ }^{14}$ BOE núm. 91, de 1 de abril de 2020.

${ }^{15}$ BOE núm. 178, de 27 de junio de 2020.

${ }^{16}$ BOE núm. 185, de 6 de julio de 2020.
} 
otras medidas, el Programa de Renovación de Vehículos 2020 (Programa RENOVE 2020), con el objetivo de apoyar la sustitución del parque de vehículos antiguos por otros de menores emisiones y de todas las tecnologías disponibles actualmente (eléctricos, híbridos, de hidrógeno, de combustión, GLP y gas natural).

- Finalmente, el Real Decreto-ley 23/2020, de 23 de junio, por el que se aprueban medidas en materia de energía y en otros ámbitos para la reactivación económica ${ }^{17}$, que merece mención aparte.

\section{REAL DECRETO-LEY 23/2020, DE 23 DE JUNIO, POR EL QUE SE APRUEBAN MEDIDAS EN MATERIA DE ENERGÍA Y EN OTROS ÁMBITOS PARA LA REACTIVACIÓN ECONÓMICA.}

La necesidad de que la transición energética actúe como "palanca verde" para la recuperación económica española, la importancia de dar cumplimento a los compromisos internacionales asumidos y seguir la senda de la hoja de ruta climática de la Unión Europea, con la presentación del nuevo Pacto Verde Europeo, y la exigencia de evitar la pérdida de "gestionabilidad" del sistema por el cierre de las centrales térmicas, son los tres motivos fundamentales que justifican las medidas contenidas en el Real Decreto-ley 23/2020, de 23 de junio.

Se trata de medidas muy variadas que se organizan en cuatro bloques. En seguida analizaremos las más importantes.

\subsection{Medidas para el desarrollo ordenado e impulso de las energías renovables}

El primer bloque (Título I) hace referencia a medidas para el desarrollo ordenado e impulso de las energías renovables. Por ello, lleva a cabo una reforma importante de los criterios de acceso y conexión a las redes de transporte y distribución, con el objetivo de ordenar una cantidad muy elevada de solicitudes de acceso a la red eléctrica por instalaciones de energías renovables, muchas de ellas con fines especulativos, que están absorbiendo la capacidad de

\footnotetext{
${ }^{17}$ BOE núm. 175, de 24 de junio de 2020.
} 
evacuación de la red. En consecuencia, el artículo 1 establece que, para mantener el acceso y la conexión a las redes de transporte y distribución de electricidad, los titulares de los permisos de acceso para las instalaciones de generación de energía eléctrica que hubieran obtenido dichos permisos en fecha posterior al 27 de diciembre de 2013 (y antes de la entrada en vigor del Real decreto-ley en objeto), deben cumplir una serie de hitos administrativos en unos plazos concretos, para acreditar la viabilidad técnica y la solidez de los proyectos. La no acreditación de estos hitos comportará la caducidad automática de los permisos de acceso y/o conexión concedidos, así como la ejecución inmediata, por el órgano competente para la emisión de las autorizaciones administrativas, de las garantías económicas presentadas para la tramitación de la solicitud de acceso a las redes de transporte y distribución, siempre que la declaración de impacto ambiental no fuera desfavorable ${ }^{18}$. A ello cabe añadir la posibilidad para los titulares de los permisos de renunciar a los mismos en un plazo de tres meses desde la entrada en vigor de la norma, procediéndose, en tal caso, a la devolución de las garantías económicas presentadas. Siempre en el mismo bloque de medidas, el artículo 2 modifica la Ley 24/2013, de 26 de diciembre, del Sector Eléctrico (en adelante LSE), añadiendo el apartado 7 bis al artículo 14. A través de esta modificación, se habilita expresamente al Gobierno para que establezca otro marco retributivo, alternativo al régimen retributivo específico, como nuevo sistema de apoyo para las tecnologías renovables, coherente con la evolución tecnológica y económica de estas tecnologías y que traslade directamente los ahorros al consumidor de electricidad. En la misma senda, el artículo 3 procede a modificar numerosos artículos ${ }^{19}$ del Real Decreto 1955/2000, de 1 de diciembre, por el que se regulan las actividades de transporte, distribución, comercialización, suministro y procedimientos de autorización de instalaciones de energía eléctrica, con el objetivo de agilizar y simplificar la tramitación de los procedimientos de autorización de la construcción, ampliación, modificación y explotación de las instalaciones eléctricas de producción, transporte y distribución.

\footnotetext{
${ }^{18}$ Tal y como se deduce por el art. 40 de la Ley 21/2013 de Evaluación Ambiental.

19 Los artículos afectados son los arts. 115, 125, 127, 131, 144, 146. Además, se añade la Disposición adicional decimocuarta y el Anexo II.
} 


\subsection{Modificación de la Ley $24 / 2013$, de 26 de diciembre, del} Sector Eléctrico para introducir las nuevas figuras de almacenamiento, hibridación, agregadores independientes y comunidades de energía renovables

El segundo bloque de medidas (Título II) pretende impulsar "nuevos modelos de negocio" a través de la introducción de disposiciones relativas al almacenamiento, agregadores independientes, comunidades de energías renovables, hibridación, infraestructuras de recarga de alta capacidad de más de $250 \mathrm{~kW}$, autorización simplificada de proyectos de $\mathrm{I}+\mathrm{D}+\mathrm{i}$, bancos de prueba regulatorios, autorización simplificada de instalaciones de red móviles, así como la optimización del uso de la capacidad de acceso concedida. En consecuencia, el artículo 4, llevando a cabo una reforma de varios artículos de la $\mathrm{LSE}^{20}$, introduce, entre otras, las figuras de

- "instalaciones de almacenamiento", que podrán ser titularidad de distintos sujetos del sistema eléctrico.

- "hibridación", es decir, el acceso a un mismo punto de la red de instalaciones que empleen distintas tecnologías de generación siempre que esto resulte técnicamente posible.

- "agregación" y "agregador independiente", sujetos que prestan servicios de agregación y que no está relacionado con el suministrador del cliente, entendiendo por agregación combinar la demanda de varios consumidores de electricidad o de varios generadores para su venta, compra o subasta en cualquier mercado de electricidad.

- "comunidades de energías renovables", que son "entidades jurídicas basadas en la participación abierta y voluntaria, autónomas y efectivamente controladas por socios o miembros que están situados en las proximidades de los proyectos de energías renovables que sean propiedad de dichas entidades jurídicas y que estas hayan desarrollado, cuyos socios o miembros sean

\footnotetext{
${ }^{20}$ Se modifica el apartado 13.b) del artículo 3 LSE, se añade un apartado d) en el apartado 4 del artículo 4, se añaden los epígrafes h), i) y j) al apartado 1 del artículo 6 , se modifica el apartado 10 del artículo 14, se añade un apartado 12 al artículo 33, se modifica el apartado 1 del artículo 49, así como los apartados 1, 2 y 3 del artículo 53, se modifica el apartado 1 del artículo 54, y se introduce una disposición adicional vigésima tercera y un anexo.
} 
personas físicas, pymes o autoridades locales, incluidos los municipios y cuya finalidad primordial sea proporcionar beneficios medioambientales, económicos o sociales a sus socios o miembros o a las zonas locales donde operan, en lugar de ganancias financieras".

Estas modificaciones - además de trasponer en el ordenamiento español las parte correspondientes de las Directivas Europeas núm. 2019/944, núm. 2012/27 relativa a la eficiencia energética (que se había traspuesto de manera incorrecta) y núm. 2018/2001 - eliminan importantes barreras para el desarrollo de las energías renovables en nuestro país. Con la misma ratio, se habilita al Gobierno para que regule un procedimiento especial de autorización de instalaciones cuyo objeto principal sea la $1+D+i$, de manera que se tengan en cuenta las singularidades de los proyectos piloto y se fomente la investigación e innovación en el ámbito del sector eléctrico. Asimismo, para impulsar la electrificación de la automoción y facilitar el despliegue de una red suficiente de estaciones de recarga de alta potencia en las vías interurbanas, se introduce la necesidad de autorización de estas y se les otorga la declaración de utilidad pública a las infraestructuras de recarga que tengan una potencia superior a $250 \mathrm{~kW}$.

\subsection{Fomento de la eficiencia energética}

El tercer bloque (Título III) tiene como objetivo el fomento de la eficiencia energética. La Ley 18/2014, de 15 de octubre, establecía un sistema nacional de obligaciones de eficiencia energética, a través del cual se asignaban a las empresas comercializadoras de gas y electricidad, a los operadores de productos petrolíferos al por mayor y a los operadores de gases licuados de petróleo al por mayor, una cuota anual de ahorro energético denominada obligación de ahorro. El artículo 69 de la Ley 18/2014 fijaba como fecha final del periodo de duración del sistema nacional de obligaciones de eficiencia energética el 31 de diciembre de 2020. Sin embargo, tras la revisión de la Directiva 2012/27/UE por la Directiva 2018/2002/UE, se ha ampliado el alcance del sistema de obligaciones de eficiencia hasta el 31 de diciembre de 2030. Por este motivo, el art. 5 del RDL 23/2020, dispone una moratoria del sistema nacional de obligaciones de eficiencia energética hasta la fecha prevista por la Directiva. Finalmente, el mismo art. 5 adapta el procedimiento de cálculo de las 
obligaciones de ahorro de cada sujeto obligado para dotar al sistema de una mayor flexibilidad, transparencia y previsibilidad.

\subsection{Modificaciones de la Ley 21/2013, de 9 de diciembre, de evaluación ambiental para agilizar el procedimiento de evaluación ambiental}

Por último, en el cuarto bloque (Título IV) se adoptan una serie de medidas sectoriales dirigidas a mitigar los efectos negativos de la situación provocada por la crisis de la Covid-19 sobre los sujetos que operan en los mercados energéticos y las destinadas a asegurar el equilibrio y la liquidez en el sistema eléctrico. Entre todas las medidas previstas, destacamos la modificación por parte del art. 8 RDL 23/2020 de algunos artículos de la Ley 21/2013, de 9 de diciembre, de evaluación ambiental (en adelante LEA), para agilizar el procedimiento de evaluación ambiental y regular la prórroga de vigencia de las declaraciones de impacto. En detalle:

- $\quad$ se modifica el art. 34 LEA que regula las consultas a las Administraciones públicas afectadas y a las personas interesadas y la elaboración del documento de alcance del estudio de impacto ambiental. Concretamente, se añade que "si la documentación inicial presentada por el promotor junto con la solicitud careciera de la información exigible o fuera insuficiente para poder efectuar las consultas a las Administraciones Públicas afectadas, se requerirá al promotor para que en el plazo improrrogable de diez días, subsane la falta de información o acompañe la documentación necesaria, con indicación de que si así no lo hiciera, se le tendrá por desistido de su solicitud". Además, en el supuesto en el que el órgano ambiental no haya recibido los informes de las Administraciones públicas afectadas relevantes para determinar el alcance del estudio de impacto ambiental, este órgano elaborará el documento, haciendo constar la ausencia de los informes solicitados. En cambio, en la regulación anterior el órgano ambiental tenía que notificarlo al promotor, quien podría elaborar el estudio de impacto ambiental y continuar con la tramitación del procedimiento. Finalmente, se añade la previsión de que el documento de alcance del estudio de impacto ambiental tendrá validez de dos años a partir del día siguiente al de su notificación al promotor y perderá su validez una vez 
que transcurra dicho plazo sin que se haya presentado ante el órgano sustantivo el estudio de impacto ambiental para iniciar el procedimiento de evaluación de impacto ambiental ordinaria.

- Se añaden los apartados 2, 3, 4 y 5 en el artículo 43 que regula la vigencia de la declaración de impacto ambiental. Aunque el plazo de vigencia sigue siendo de cuatro años, se regula la prórroga de vigencia de las declaraciones de impacto. De tal manera, el promotor puede solicitar una prórroga de dos años de la vigencia de la declaración de impacto ambiental antes de que transcurra el plazo de vigencia de cuatro años, siempre y cuando no se hayan producido cambios sustanciales en los elementos esenciales que sirvieron para realizar la evaluación de impacto ambiental. La solicitud formulada por el promotor suspenderá el plazo de vigencia de cuatro años. La solicitud de prórroga deberá ser resulta por el órgano ambiental en un plazo de tres meses desde la fecha de presentación de dicha solicitud, tras solicitar los informes a las Administraciones públicas afectadas por razón de la materia en relación con los elementos esenciales que sirvieron para realizar la evaluación de impacto ambiental. Éstas deberán pronunciarse en el plazo de treinta días, ampliables por quince días más, por razones debidamente justificadas, periodo durante el cual el plazo de resolución de la solicitud permanecerá suspendido. Transcurrido el plazo sin que el órgano ambiental haya resuelto se entenderá desestimada la solicitud de prórroga de la vigencia de la declaración de impacto ambiental.

- Se modifican los apartados 2, 8 y 9 del artículo 47, sobre el informe de impacto ambiental en el ámbito de la evaluación de impacto ambiental simplificada. En primer lugar, se añade la posibilidad que el órgano ambiental, motivando la imposibilidad de dictar una resolución fundada sobre los posibles efectos adversos del proyecto sobre el medio ambiente, al no disponer de elementos de juicio suficientes, pueda terminar el procedimiento con archivo de actuaciones. En segundo lugar, en consideración con la prórroga del informe de impacto ambiental, se establece que el plazo de resolución de la solicitud permanecerá suspendido por el plazo (de 30 días más 15, por razones justificadas) que tienen las Administraciones Públicas afectadas para enviar los informes requeridos por el órgano ambiental. Una vez transcurrido el plazo sin que el órgano ambiental haya resuelto sobre la prórroga de la 
vigencia del informe de impacto ambiental, la solicitud de prórroga se entenderá desestimada (y no estimada, como en la anterior versión de la disposición).

\subsection{Medidas de impulso a la transición "justa"}

Al conjunto de medidas hasta ahora examinadas, deben sumarse aquellas relativas a promover una transición justa. En nuestra crónica del primer semestre de $2020^{21}$, relatamos que el Ministerio para la Transición Ecológica y el Reto Demográfico estaba tramitando las solicitudes de cierre de ocho de las catorce centrales de carbón existentes en la península. En los seis meses que cubre esta crónica, como se ha relatado con anterioridad, la Dirección General de Política Energética y Minas ha autorizado el cierre de cinco de ellas. Pues, el repentino cierre de las centrales térmicas de carbón tiene ya de por sí un fuerte impacto en la situación económica de determinadas comarcas de España en la que sus ciudadanos dependen de los puestos de trabajo generados directa 0 indirectamente por estas centrales de producción. A ello cabe ahora sumar los importantes efectos económicos negativos provocados por la pandemia. El Real Decreto-ley 17/2019, de 22 de noviembre, que analizamos debidamente a su tiempo ${ }^{22}$, intervino justamente para impulsar la reactivación industrial en estas comarcas. En concreto, el RDL 17/2019 permitía al Ministerio para la Transición Ecológica regular procedimientos y establecer requisitos para que, a la hora de otorgar una nueva concesión de acceso a un proyecto de energías renovables en los nudos donde se acometan cierres, se tengan en cuenta criterios sociales, incluyendo el potencial de generación de empleo, y criterios medioambientales. Sin embargo, para poder diseñar esos procedimientos, resulta necesario conocer en esos nudos concretos la capacidad de acceso existente, tomando en consideración la evolución de la tecnología y de los criterios técnicos y de seguridad. Por este motivo, la disposición adicional primera del RDL 23/2020 habilita a la Dirección General de Política Energética y Minas a pedir al operador del sistema para que informe de la capacidad de acceso individualizada de estos

\footnotetext{
${ }^{21}$ Laura Presicce, "Legislación básica de protección del medio ambiente. Primer semestre 2020", cit., p. 8.

${ }^{22}$ Laura Presicce, "Legislación básica de protección del medio ambiente. Primer semestre 2020", cit., pp. 8 ss.
} 
"nudos de transición justa". En los cálculos efectuados, el operador del sistema deberá considerar la situación concreta de cada uno de estos nudos y de aquellos que tengan influencia sobre ellos. Asimismo, la disposición final segunda del RD 23/2020 modifica el objeto del antiguo "Instituto para la Reestructuración de la Minería del Carbón y del Desarrollo Alternativo de las Comarcas Mineras", denominado ahora "Instituto para la Transición Justa, O.A." ${ }^{23}$ para que, debido a las similitudes presentadas, se ocupe también de los trabajadores y territorios afectados por el cierre de las centrales térmicas.

Finalmente, resulta oportuno traer a colación la disposición adicional tercera que habilita a la Ministra para la Transición Energética y Reto Demográfico para utilizar el superávit de ingresos del sistema eléctrico para cubrir los desajustes temporales, con carácter preferente, y las desviaciones transitorias entre ingresos y costes de los ejercicios 2019 y 2020 - y la disposición transitoria primera - que introduce una moratoria de nuevos permisos de acceso, con excepciones, hasta la aprobación de la nueva normativa de otorgamientos de permisos de acceso -.

\section{NOVEDADES NORMATIVAS EN ÁMBITOS SECTORIALES}

\subsection{En materia de residuos y suelos contaminados}

En materia de residuos y suelos contaminados, tres Reales Decretos en particular merecen una consideración especial. Se trata del Real Decreto $553 / 2020$, de 2 de junio, por el que se regula el traslado de residuos en el interior del territorio del Estado ${ }^{24}$; del Real Decreto 646/2020, de 7 de julio, por el que se regula la eliminación de residuos mediante depósito en vertedero ${ }^{25}$; y del Real Decreto 731/2020, de 4 de agosto, por el que se modifica el Real Decreto 1619/2005, de 30 de diciembre, sobre la gestión de neumáticos fuera de uso ${ }^{26}$.

\footnotetext{
${ }^{23}$ Por el Real Decreto 500/2020, de 28 de abril, por el que se desarrolla la estructura orgánica básica del Ministerio para la Transición Ecológica y el Reto Demográfico, y se modifica el Real Decreto 139/2020, de 28 de enero, por el que se establece la estructura orgánica básica de los departamentos ministeriales.

${ }^{24}$ BOE núm. 171, de 19 de junio de 2020.

${ }^{25}$ BOE núm. 187, de 8 de julio de 2020.

${ }^{26}$ BOE núm. 213, de 7 de agosto de 2020.
} 
Los citados Reales Decretos contribuyen, sin duda, a dar cumplimento a la nueva Estrategia Española de Economía Circular, aprobada por el Consejo de Ministros el 2 de junio de $2020^{27}$, y sientan las bases para la futura Ley de Residuos y Suelos Contaminados.

a) Real Decreto 553/2020, de 2 de junio, por el que se regula el traslado de residuos en el interior del territorio del Estado

La Ley 22/2011, de 28 de julio, de residuos y suelos contaminados (en adelante LRSC), en cumplimiento del artículo 33 del Reglamento comunitario núm. 1013/2006 del Parlamento Europeo y del Consejo, de 14 de junio de 2006, relativo a los traslados de residuos, incluyó en su artículo 25, la definición del traslado de residuos en el interior del Estado ("el transporte de residuos desde una comunidad autónoma a otra, para su valorización o eliminación") así como su régimen jurídico. El Real Decreto 553/2020, de 2 de junio, desarrolla lo previsto en el citado artículo 25, respetando la estructura y líneas generales del Real Decreto 180/2015, de 13 de marzo, por el que se regula el traslado de residuos en el interior del territorio del Estado, para mejorar el procedimiento y la trazabilidad de los traslados desde el lugar de origen del residuo hasta el destino final, para asegurar un correcto tratamiento de los residuos y para que sea más fiel al Reglamento comunitario.

El Real Decreto se compone de tres capítulos. En el primero, se hallan las disposiciones de carácter general; en el segundo, los requisitos comunes a todos los traslados; y el tercero se refiere al caso específico de los traslados que requieren que se efectúe una notificación previa a los órganos competentes de las comunidades autónomas. La norma se aplica a los traslados de residuos entre comunidades autónomas para su valorización o eliminación, incluidos los traslados que se producen a instalaciones que realizan operaciones de tratamiento intermedio y de almacenamiento.

En primer lugar, el Real Decreto precisa que no tienen la consideración de traslado de residuos (art. 1), al entenderse que se trata de acopio de residuos,

\footnotetext{
$27 \quad$ Consultable en: $\quad<$ https://www.miteco.gob.es/es/calidad-y-evaluacionambiental/temas/economia-circular/espanacircular2030 def1 tcm30-509532.PDF> (última consulta: 01.10 .2020$)$.
} 
las actividades de transportes de residuos de empresas de instalación o mantenimiento desde el lugar donde se ha producido hasta su propia instalación, el traslado de residuos en los procesos de logística inversa y el transporte de residuos por particulares hasta puntos de recogida.

En segundo lugar, el art. 2 detalla quién puede ser, en el orden establecido por el mismo artículo, operador de traslado; es decir, la persona física o jurídica que pretende realizar un traslado o hacer que se lleve a cabo un traslado de residuos para su tratamiento, y en quien recae la obligación de notificar el traslado. En los residuos de competencia municipal, el operador del traslado será la entidad local. En el caso en que dicha competencia se lleve a cabo de manera indirecta, la entidad local podrá autorizar por escrito a la empresa que presta dicho servicio para que actúe en su nombre como operador del traslado.

En tercer lugar, se regula, a través del art. 5, el contenido del contrato de tratamiento, definido como (art. 2.h) "el acuerdo entre el operador y el gestor de una instalación de tratamiento de residuos por el que este se compromete a tratar los residuos una vez que han sido aceptados, y en el que se establece, al menos, las especificaciones de los residuos, las condiciones del traslado y las obligaciones de las partes cuando se presenten incidencias, en particular, en el caso del rechazo del residuo por el destinatario". Este contrato debe ahora incluir las instalaciones de origen y destino, el tipo de residuos y las condiciones de aceptación.

En cuarto lugar, se establece que para determinados tipos de residuos (detallados e el art. 3.2, entre los cuales los residuos peligrosos), deberá realizarse una notificación previa a las Comunidades Autónomas de origen y destino, al menos diez días antes del traslado. Las CCAA de origen y destino dispondrán de diez días para manifestar su oposición al traslado (art. 9), transcurridos los cuales, a falta de oposición expresa, el operador podrá efectuar el traslado. La notificación podrá servir para múltiples traslados siempre que los residuos tengan características físicas y químicas similares y se trasladen al mismo destinatario y a la misma instalación. Esta notificación se denominará notificación general y tendrá un plazo de vigencia máximo de tres años.

Además, durante el traslado todos los residuos deberán ir acompañados por un Documento de Identificación (art. 6), que será diferente en función de si el tipo 
de residuo precisa o no notificación previa (Anexo I y Anexo III). El Documento de Identificación permite conocer en todo momento el tipo de residuo, su origen y destino, el operador del traslado, los datos del transportista y cualquier otra circunstancia inherente al movimiento de los residuos. De tal manera, resulta esencial para la adecuada trazabilidad y para facilitar a las Administraciones sus funciones de control, vigilancia e inspección. En caso de traslados de residuos de competencia municipal que requieren de notificación previa, el documento de identificación será único para varios traslados siempre y cuando coincidan el origen y el destino, indicándose la cantidad prevista a trasladar en un mes por vehículo. En cambio, el documento de identificación podrá tener validez trimestral si el traslado de residuos municipales no requiera de notificación previa. El art. 7 regula el supuesto del rechazo de los residuos en la planta de tratamiento a la que se han trasladado.

Cabe destacar también la introducción del procedimiento electrónico (Disposición Adicional primera). La tramitación electrónica del procedimiento de traslado se llevará a cabo a través del "eSIR» (Sistema de Información de Residuos) y, además, se creará un repositorio con las notificaciones previas y los documentos de identificación asociados, que permitirá el análisis de movimiento de residuos dentro del estado y que facilitará las labores de control e inspección.

Finalmente, las Disposiciones Adicionales segunda y tercera, se ocupan relativamente del traslado de residuos dentro de una misma CCAA o entre CCAA pero con tránsito en otro país. La Disposición adicional cuarta define quien será el productor inicial en los traslados de residuos de construcción y demolición y la Disposición adicional sexta se refiere a la posibilidad, por parte del Director General de Calidad y Evaluación Ambiental de establecer, en colaboración con las CCAA, documentos de traslado específicos en caso de recogida de residuos a múltiples productores en un mismo vehículo.

EL RD objeto de análisis deroga en particular el Real Decreto 180/2015, de 13 de marzo, por el que se regula el traslado de residuos en el interior del territorio del Estado. 
b)

Real Decreto 646/2020, de 7 de julio, por el que se regula la eliminación de residuos mediante depósito en vertedero

El Real Decreto 646/2020, de 7 de julio, por el que se regula la eliminación de residuos mediante depósito en vertedero, que trae fundamento en la disposición final tercera de la Ley 22/2011, de 28 de julio, de residuos y suelos contaminados (LRSC) tiene como fin último avanzar hacia una economía circular y cumplir con la jerarquía de residuos y con los requisitos de eliminación establecidos en los artículos 8 y 23 de la misma LRSC. En consecuencia, establece un marco jurídico y técnico adecuado para las actividades de eliminación de residuos mediante depósito en vertederos de conformidad con la LRSC al tiempo que regula las características de los vertederos y su correcta gestión y explotación. Asimismo, se propone garantizar una reducción progresiva de los residuos depositados en vertedero, especialmente de aquellos que son aptos para su preparación para la reutilización, reciclado y valorización, mediante el establecimiento de requisitos técnicos y operativos rigurosos aplicables tanto a los residuos como a los vertederos.

Su art. 2 define, entre otros, "residuo municipal" y "vertedero". Respecto a este último, la definición comprende las instalaciones donde se almacenan residuos peligrosos, dentro o fuera del lugar de producción, por un periodo de tiempo superior a 6 meses, así como las instalaciones que almacenan residuos no peligrosos, dentro y fuera del lugar de producción de los mismos, por un periodo de tiempo superior a 1 año si el destino previsto para los mismos es la eliminación y 2 años si el destino previsto es la valorización. En cambio, no tienen la consideración de vertederos las instalaciones donde los residuos son descargados y acondicionados para su transporte a otras instalaciones donde son valorizados, tratados o eliminados.

Los vertederos se clasifican (art. 5) en vertederos para residuos peligrosos, para residuos no peligrosos, para residuos inertes y, en el art. 7, se detallan qué tipo de residuos podrán admitirse en las distintas clases de vertedero. Sin embargo, en ninguno de ellos serán admitidos los residuos indicados en el art. 6, entre los cuales residuos líquidos y residuos inflamables, explosivos o corrosivos, neumáticos usados enteros y neumáticos usados troceados - con exclusión los 
neumáticos de bicicleta - y, con excepciones, residuos recogidos separadamente para la preparación para la reutilización y el reciclado. Además, antes del 1 de enero de 2023, por orden ministerial, se aprobará una relación de residuos que no se aceptarán en vertedero, por tratarse de residuos aptos para la preparación para la reutilización, el reciclado u otro tipo de valorización, en particular para los residuos municipales.

El art. 8 incorpora los objetivos de reducción del vertido de residuos municipales establecidos en la Directiva (UE) 2018/850, del Parlamento Europeo y del Consejo, de 30 de mayo de 2018, en el contexto del impulso al tránsito a la economía circular, así como la metodología de cálculo establecida en la Decisión de ejecución (UE) 2019/1885 de la Comisión, de 6 de noviembre de 2019. Asimismo, siempre en el marco de impulsar la economía circular, se concreta el régimen de los costes de vertido (art. 9), es decir el precio que la entidad explotadora cobra por la eliminación de los residuos. La adecuada fijación de los precios de vertido contabilizando la totalidad de los costes directos e indirectos es uno de los instrumentos más eficientes para la aplicación de la jerarquía de residuos, especialmente para la prevención de residuos y la promoción del reciclado. Entre los costes indirectos, se ha especificado la obligación de contabilizar aquellos ligados a la emisión de gases de efecto invernadero para los que ya existe un coste medioambiental aceptado por la Unión Europea a través de su mercado de carbono. Además, el apartado tercero del art. 9 establece que, cuando sea pertinente, las cantidades recaudadas se destinen a la promoción de las primeras opciones de la jerarquía de residuos de forma que se avance en un reciclado de calidad, así como en la mejora de la gestión de residuos, incluyendo la restauración ambiental de espacios degradados por vertidos y la descontaminación de suelos.

El Capítulo III disciplina el régimen de autorización de los vertederos y de las entidades explotadoras y el Capítulo IV se centra en la admisión de los residuos en vertederos, remitiendo, además, entre otras cosas, al control de la documentación de los residuos entregados que se ha analizado anteriormente (RD 553/2020, de 2 de junio).

El Capítulo V regula el procedimiento de control y vigilancia durante la fase de explotación del vertedero y el procedimiento de clausura y mantenimiento post- 
clausura. El procedimiento de clausura podrá iniciarse por el titular del vertedero, a petición de la entidad explotadora o por decisión motivada de la autoridad competente. El vertedero sólo podrá considerarse definitivamente clausurado después de que la autoridad competente haya realizado una inspección final in situ, haya evaluado todos los informes presentados por la entidad explotadora y le haya comunicado la aprobación de la clausura efectuada. La comunicación de la aprobación de la clausura no podrá demorarse más de tres años desde la realización de la inspección final in situ y no disminuirá en ningún caso la responsabilidad de la entidad explotadora. Sin embargo, tras la clausura definitiva del vertedero la entidad explotadora seguirá siendo responsable de las tareas de mantenimiento adecuadas y de las tareas de vigilancia y control post clausura. La duración de estas obligaciones será fijada por la autoridad competente teniendo en cuenta el tiempo durante el cual el vertedero puede entrañar un riesgo significativo para la salud de las personas o el medio ambiente, pero en ningún caso este periodo podrá ser inferior a treinta años.

De igual manera, debemos reseñar la importancia de que los vertederos se sometan a inspecciones periódicas (Capítulo VI). El Real Decreto 1481/2001, de 27 de diciembre, ya contemplaba un régimen de inspección por parte de las autoridades ambientales para la comprobación del cumplimiento de los procedimientos de admisión de residuos en vertedero. Este real decreto refuerza dicho aspecto mediante el establecimiento de la obligación de que las instalaciones de vertido sean sometidas a inspección periódica por las autoridades competentes tanto en fase de explotación como en el periodo de vigilancia post-clausura, cuyo alcance y periodicidad mínima se detallan en anexo VII del RD en objeto.

Finalmente, el Capítulo VII se refiere a las obligaciones de información. El Ministerio para la Transición Ecológica y el Reto Demográfico deberá remitir por medios electrónicos a la Comisión Europea información anual sobre los objetivos para reducir los residuos municipales biodegradables destinados a vertedero y sobre los objetivos de vertido del artículo 8. Por ello, las comunidades autónomas deberán transmitir anualmente por medios electrónicos al Ministerio para la Transición Ecológica y el Reto Demográfico la información indicada en el art. 19. 
La norma objeto de análisis deroga el Real Decreto 1481/2001, de 27 de diciembre, por el que se regula la eliminación de residuos mediante depósito en vertedero.

el que se modifica el Real Decreto 1619/2005, de 30 de diciembre, sobre la gestión de neumáticos fuera de uso

Así como el RD anterior, el Real Decreto 731/2020, de 4 de agosto, contiene varias medidas encaminadas a acelerar la transición hacia un modelo de economía circular, en este caso del sector de los neumáticos fuera de uso. La presente norma modifica el Real Decreto 1619/2005, de 30 de mayo, pero no constituye una norma de incorporación parcial de la Directiva 2018/851/UE, del Parlamento Europeo y del Consejo, de 30 de mayo de 2018, por la que se modifica la Directiva 2008/98/CE sobre los residuos.

Como se ha observado en relación con el RD 553/2020, los neumáticos usados enteros y troceados - con exclusión los neumáticos de bicicleta -, no serán admitidos en ningún vertedero (art. 6 RD 553/2020).

En este sentido, el Real Decreto 731/2020 prohíbe el depósito en vertederos de los neumáticos de gran tamaño (con diámetro superior a 1.400 milímetros) y su incorporación al sistema de gestión bajo la responsabilidad ampliada del productor, de manera que todos los neumáticos de reposición - a excepción de las ruedas de las bicicletas - pasan ahora a ser gestionados para su reutilización o reciclado. La normativa establece, por ende, como prioridad la reutilización de los neumáticos, concretando las condiciones que deben reunir los neumáticos de segundo uso y los recauchutados para su posterior comercialización.

Además, el RD define (para cada año y en cada CCAA) las responsabilidades de recogida y gestión que corresponden a los sistemas colectivos de responsabilidad ampliada del productor. Esto evitará problemas de acumulación y retrasos en la recogida de los residuos en los puntos de generación.

Otro objetivo del RD es ampliar las responsabilidades de los productores de neumáticos, a través de un conjunto de medidas que aumenta las obligaciones de gestión. Entre todas, destacamos que los productores deben gestionar los 
neumáticos cuantas veces sea necesario hasta su completa valorización, incluyendo la gestión del neumático si vuelve a ser comercializado como producto de segunda mano o recauchutado.

Por último, el RD regula también el procedimiento excepcional de recogida en los puntos limpios de los neumáticos fuera de uso, así como la relación entre los puntos limpios y productores para costear la recogida y tratamiento de dichos neumáticos.

d) Otras normas en materia de residuos y suelos contaminados

Además de las normas analizadas, siempre en materia de residuos, mencionamos:

- La Orden TED/363/2020, de 20 de abril, por la que se modifican la Orden APM/205/2018, de 22 de febrero, por la que se establecen los criterios para determinar cuándo el aceite usado procesado procedente del tratamiento de aceites usados para su uso como combustible deja de ser residuo con arreglo a la Ley $22 / 2011$, de 28 de julio, de residuos y suelos contaminados; y la Orden APM/206/2018, de 22 de febrero, por la que se establecen los criterios para determinar cuándo el fuel recuperado procedente del tratamiento de residuos MARPOL tipo c para su uso como combustible en buques deja de ser residuo con arreglo a la Ley 22/2011, de 28 de julio, de residuos y suelos contaminados 28 .

- La Orden TED/426/2020, de 8 de mayo, por la que se establecen los criterios para determinar cuándo el papel y cartón recuperado destinado a la fabricación de papel y cartón deja de ser residuo con arreglo a la Ley 22/2011, de 28 de julio, de residuos y suelos contaminados ${ }^{29}$.

\subsection{En materia de eficiencia energética.}

En materia de eficiencia energética, en el semestre de referencia, deben resaltarse dos importantes Reales Decretos, ambos aprobados el 4 de agosto. 
El Real Decreto 736/2020, de 4 de agosto, por el que se regula la contabilización de consumos individuales en instalaciones térmicas de edificios ${ }^{30}$, completa la transposición de la Directiva 2012/27/UE, así como la transposición parcial de la Directiva (UE) 2018/2002, por la que se modifica la Directiva 2012/27/UE relativa a la eficiencia energética. El Real Decreto fija la obligación de los usuarios finales de calefacción y refrigeración de instalar contadores individuales, siempre que sea técnicamente viable y económicamente rentable, de manera que se permita a dicho usuario final conocer y optimizar su consumo real de energía. De igual forma, establece obligaciones en relación con la lectura de los equipos de contabilización, que deberán disponer de servicio de lectura remota que permita la liquidación individual de los costes de climatización en base a dichos consumos, al menos una vez cada dos meses.

Con el objetivo de fomentar la eficiencia energética (y contribuir a la reactivación económica) se ha aprobado también el Real Decreto 737/2020, de 4 de agosto, por el que se regula el programa de ayudas para actuaciones de rehabilitación energética en edificios existentes y se regula la concesión directa de las ayudas de este programa a las comunidades autónomas y ciudades de Ceuta y Melilla ${ }^{31}$. El programa de ayudas introducido por el Real Decreto permite llevar a cabo actuaciones de rehabilitación energética en edificios existentes, con independencia de su uso y de la naturaleza jurídica de sus titulares, con el fin de favorecer la reducción del consumo de energía final y de las emisiones de dióxido de carbono, mediante el ahorro energético, la mejora de la eficiencia energética y el aprovechamiento de las energías renovables. De este modo, el programa de ayudas contribuye a alcanzar los objetivos de reducción del consumo de energía final que establece el artículo 7 de la Directiva 2012/27/UE, de 25 de octubre de 2012.

\subsection{En materia de sanidad vegetal y especies alóctonas}

En materia de sanidad vegetal y especies alóctonas reseñamos:

\footnotetext{
30 BOE núm. 212, de 6 de agosto de 2020.
}

${ }^{31}$ BOE núm. 212, de 6 de agosto de 2020. 
- El Real Decreto 491/2020, de 21 de abril, por el que se modifica el Real Decreto 23/2016, de 22 de enero, por el que se establece el programa nacional de control y erradicación de Trioza erytreae, y el programa nacional de prevención de Diaphorina citri y Candidatus Liberibacter spp.

- El Real Decreto 429/2020, de 3 de marzo, por el que se aprueba el Reglamento sobre acceso a los recursos fitogenéticos para la agricultura y la alimentación y a los cultivados para utilización con otros fines, y se modifican diversos reales decretos en materia de productos vegetales ${ }^{32}$.

- El Real Decreto 570/2020, de 16 de junio, por el que se regula el procedimiento administrativo para la autorización previa de importación en el territorio nacional de especies alóctonas con el fin de preservar la biodiversidad autóctona española ${ }^{33}$. En concreto, el objeto de este Real Decreto es regular el procedimiento administrativo para autorizar la importación en el territorio nacional de ejemplares vivos -o de sus restos o propágulos que pudieran sobrevivir o reproducirse-, de las especies alóctonas silvestres que figuran en el Listado de especies alóctonas potencialmente susceptibles de competir con las especies silvestres autóctonas, alterar su pureza genética o los equilibrios ecológicos, de conformidad con el artículo 54.2, 3 y 4 de la Ley 42/2007, de 13 de diciembre, del Patrimonio Natural y de la Biodiversidad.

\section{ULTERIORES DISPOSICIONES DE INTERÉS PARA LA PROTECCIÓN DEL MEDIO AMBIENTE}

Por último, señalamos las siguientes disposiciones, que pueden resultar de interés para la protección del medio ambiente:

- Real Decreto 451/2020, de 10 de marzo, sobre control y recuperación de las fuentes radiactivas huérfanas ${ }^{34}$.

- Real Decreto 569/2020, de 16 de junio, por el que se regula el programa de incentivos a la movilidad eficiente y sostenible (Programa MOVES II) y se

\footnotetext{
${ }^{32}$ BOE núm. 112, de 22 de abril de 2020.

${ }^{33}$ BOE núm. 184, de 4 de julio de 2020.

${ }^{34}$ BOE núm. 117, de 12 de abril de 2020.
} 
acuerda la concesión directa de las ayudas de este programa a las comunidades autónomas y a las ciudades de Ceuta y Melilla ${ }^{35}$.

- Orden APA/423/2020, de 18 de mayo, por la que se establece un plan de gestión para la conservación de los recursos pesqueros demersales en el mar Mediterráneo ${ }^{36}$.

- Orden PCM/831/2020, de 7 de septiembre, por la que se modifica el anexo I del Real Decreto 20/2017, de 20 de enero, sobre los vehículos al final de su vida útili ${ }^{37}$.

- Orden PCM/390/2020, de 5 de mayo, por la que se modifica el anexo III del Real Decreto 219/2013, de 22 de marzo, sobre restricciones a la utilización de determinadas sustancias peligrosas en aparatos eléctricos y electrónicos ${ }^{38}$.

- Orden PCM/810/2020, de 31 de agosto, por la que se modifican los Anexos III y IV del Real Decreto 219/2013, de 22 de marzo, sobre restricciones a la utilización de determinadas sustancias peligrosas en aparatos eléctricos y electrónicos ${ }^{39}$.

- Orden DSA/819/2020, de 3 de septiembre, por la que se regula la composición y funcionamiento del Consejo de Desarrollo Sostenible ${ }^{40}$.

\footnotetext{
${ }^{35}$ BOE núm. 169, de 17 de junio de 2020.

${ }^{36}$ BOE núm. 142, de 20 de mayo de 2020.

${ }^{37}$ BOE núm. 242, de 10 de septiembre de 2020.

${ }^{38}$ BOE núm. 126, de 6 de mayo de 2020.

${ }^{39}$ BOE núm. 235, de 6 de septiembre de 2020.

${ }^{40}$ BOE núm. 239, de 7 de septiembre de 2020.
} 